Article

\title{
Knowledge, Attitude and Practice of Standard Infection Con- trol Precautions among Health-care Workers in a hospital in Qassim, Saudi Arabia: a Cross-sectional Survey
}

\author{
Adil Abalkhail ${ }^{1}$, Mahmudul Hassan Al Imam ${ }^{2,3}$, Yousif Mohammed Elmosaad ${ }^{4}$, Mahmoud F Jaber', Khaled Al Ho- \\ sis $^{5}$, Fahad A Alhumaydhi ${ }^{6}$, Thamer Alslamah ${ }^{1}$ and Ilias Mahmud ${ }^{1}$
}

\author{
${ }^{1}$ Department of Public Health, College of Public Health and Health Informatics, Qassim University, Al Bukairi- \\ yah, Saudi Arabia, Email: A.A: abalkhail@qu.edu.sa; M.J. mf.jaber@qu.edu.sa; T.A.: 4037@qu.edu.sa; I.M.: \\ i.emdadulhaque@qu.edu.sa \\ 2School of Health, Medical and Applied Sciences, Central Queensland University, Rockhampton, Queensland, \\ Australia, Email: m.alimam@cqu.edu.au \\ ${ }^{3}$ Central Queensland Public Health Unit, Central Queensland Hospital and Health Service, Rockhampton, \\ Queensland, Australia \\ 4College of Applied Medical Sciences, King Faisal University Al Hufuf, Saudi Arabia, email : yousifm_34@hot- \\ mail.com \\ ${ }^{5}$ Department of nursing education, Nursing college, Qassim university, Buraidah 51452, Saudi Arabia, \\ 3747@qu.edu.sa \\ ${ }^{6}$ Department of Medical Laboratories, College of Applied Medical Sciences, Qassim University, Buraydah, \\ Saudi Arabia, Email: f.alhumaydhi@qu.edu.sa
}

\begin{abstract}
Hospital-acquired infections (HAIs) contribute to increased length of hospital stay, high mortality and higher health-care costs. Prevention and control of HAIs is a critical public health concern. We conducted a cross-sectional survey of 213 hospital health-care workers in Qassim, Saudi Arabia. We assessed Knowledge, Attitude and Practice (KAP) of standard infection control precautions using a structured questionnaire. Predictors of KAP were investigated using multivaraible logistic regression analyses and independent sample $t$ tests. Prevalence of good $(\geq 80 \%$ correct response) knowledge, attitude and practice were $67.6 \%, 61.5 \%$ and $73.2 \%$, respectively. Predictors of good knowledge included age over 34 years (adjusted odds ratio: 30.5, $p<0.001$ ), and receiving training $(13.3, p<0.001)$. Predictor of positive attitude was having $>6$ years of experience (5.5, $p<0.001)$. While, the predictors of good practice were having $>6$ years of experience $(2.9, p<0.01)$, previous exposure to HAIs $(2.5, p<0.05)$ and training $(3.5, p<0.01)$. However, being female $(0.22$, $p<0.001)$ and older ( $>34$ years) $(0.34, p<0.01)$ were negatively associated with knowledge. Results indicate that older academic programs might not have adequately covered infection crontrol. Arranging training for HCWs might be useful in improving their knowledge of standard infection control precautions and is also expected to facilitate positive attitude and practice.
\end{abstract}




\section{Background}

The infections acquired in, or associated with, hospitals that were absent or not incubating at the time of hospital admission are defined as hospital-acquired infections (HAIs) [1]. The burden of HAIs is on the rise globally despite advancements in medical care and technologies [2]. According to the World Health Organization (WHO), the prevalence of HAIs ranges between $5.7 \%$ and $19.1 \%$ in hospital seetings globally [3]. Recent studies estimated the prevealnce of HAIs in Europe [4] and the USA [5] at $6.5 \%$ and $3.2 \%$, respectively. The burden of HAIs is strikingly higher in low-resourced countries compared to high-income countries [6-8]. A WHO-led systematic review revealed that the prevalence of HAIs varies between $7.6 \%$ and $15.5 \%$ in high-income and low-and middle income countries, respectively [3]. HAIs contribute to increased length of hospital stay, high mortality, higher health-care costs, and economic burden on families, communities, and countries at large $[3,9]$. Hence, prevention and control of HAIs appear as a critical public health concern [10].

The contaminated hands of health-care workers (HCWs) and healthcare equipments have been identified as the primary sources of HAIs $[7,11]$. The pathogens of HAIs are commonly transmitted from one patient to another when HCWs do not perform hand hygine properly following caring for one patient and contacting another patient [12]. The incidence of HAIs varies in different types of clinical departments. A study in Norway reported that the greatest infection rate is in the intensive care units followed by neonatal and burns units [13].

The WHO reported that improper environmental hygiene and waste disposal procedures, poor infrastructure, inadequatre equipment and manpower, overcrowding, limited knowledge and poor practices of basic infection control measures, and lack of national guidelines are the key determinants of HAIs [14]. The Center for Disease Control and Prevention (CDC) developed 'Standard Precautions' describing detailed procedures that need to be followed in order to prevent transmission of disease-causing agents and thereby preventing HAIs [15]. The standard infection control precautions warrant a uniform protocol to be followed for all patients at all times in all settings [2]. The principle of this guideline is all patients carry infectious agents even when they are asymptomatic [15]. The standard precautions include hand hygiene, use of gown, cleaning and disinfection of equipment, facial protection (e.g. masks and goggles), disposal of sharp objects, management of medical waste and coughing etiquette [2]. However, Hein and colleagues [16] reported that adherence to hand hygiene recommendations among HCWs is below standard, with a $30 \%$ compliance rate in Burkina Faso. It was found that about $42 \%$ of Corona Virus Disease-2019 among HCWs is associated with improper personal protective equipment (PPE) use [17]. Hefty workload, prolong clinical methods and skin status have been reported as key barriers in maintaining hand hygiene recommendations [18,19].

In some urban hospitals in the Kingdom of Saudi Arabia (KSA) recorded 2.2\% hospital infection monthly, and other reports confirmed that hospital infection is still one of the most common health problems in the KSA [20]. Al Ra'awji et al. [21] observed that more than one quarter $(37 \%)$ of HCWs in the KSA had poor knowledge on hand hygiene and there is a high need of training for the HCWs in this country. The KSA has been trying to activate all infection control guidelines to improve the activities in the field of infection control in high standards [22].

According to WHO, poor knowledge, attitude and practices (KAP) are among the key predictors of HAIs [14]. While narrating the KAP theory, Kelman argued that knowledge is essential to change practice and a positive attitude is a key instigator to bring a change $[23,24]$. Therefore, assessment of KAP among the HCWs is crucial to explore the reasons for non-compliance and identify the measures that should be undertaken to improve infection control practice and prevent HAIs [12]. Our literature search revealed a few studies reporting the KAP of hand hygiene and infection control mesures in the KSA. Among the published studies, one focused on hand hygiene of HCWs [21], three studied infection control among dental students [25-27], one assessed infection control measures among HCWs in dental clinics [28], one investigated cross-infection and infection control 
in dental patients [29], one incorporated health science students to assess standard precautions and infection control [30] and one evaluated prevention and control of HAIs among HCWs and non-HCWs [22]. Although, Al Ra'awji et al. [21] studied KAP of hand hygiene among HCWs but the authors did not report practice aspects. To the best of our knowledge, no study has examined the KAP on standard precautions of infection control among HCWs in the KSA. In this context, we aimed to assess the current status of KAP regarding infection control standard precautions among HCWs in the Qassim University Medical City, KSA.

\section{Methods}

\section{Study Design and Setting}

We conducted a cross-sectional survey of the HCWs in the Qassim university medical city, Saudi Arabia between November 2020 and February 2021. Qassim university medical city is the first specialized academic medical city in the Qassim region, KSA. It has $278 \mathrm{HCWs}$ including physicians of different disciplines, dentists, nurses and pharmacist and medical technologists [https://qumc.edu.sa/].

\section{Instrument}

We assessed Knowledge, Attitude and Practices (KAP) of standard infection control precautions using a self-administered structured questionnaire. We developed our KAP questions on infection control standard precaution based on the guideliens of the CDC [31] and WHO [32]. The questionnaire was divided into four parts: the first part included questions on demographic and professional information of the HCWs; the second, third and fourth parts respectively focused on knowledge, attitude and practices regarding infection control standard precautions.

We assesed knowledge using a 20 item-scale. We provided 1 point for each right answer and 0 point for each wrong answer. The maximum possible score was 20 points with a range from $0-20$ points. Overall level of knowledge were classified as poor $(<10$ points, $<50 \%$ right answer), moderate (10 - 15 points, $50-79 \%$ right answer) and good (16- 20 points, $80-100 \%$ right answer). For logistic regression analysis knowledge was recoded into two groups - good (16 - 20 points, $80-100 \%$ right answers) and moderate to poor $(<16$ points, $<80 \%$ right answers).

We used 14 statements to assess HCWs attitude towards infection control standard precuations. Each statement was assessed on a five-point Likert type scale (strongly disagree to strongly agree). The maximum possible score was 70 points with a range from 14 -70 points. Attitudes were classified as poor ( $<35$ points, $<50 \%$ score), moderate $(35-55$ points, $50-79 \%$ score) and positive ( $36-70$ points, $80-100 \%$ score). For logistic regression analysis attitude was recoded into two groups - positve (56- 70 points, $80-100 \%$ score) and poor to moderate ( $<56$ points, $<80 \%$ score).

We assesed practice of infection control standard precautions using 15 questions on practicing standard precautions. Participants were given 1 point for each activities they were always practicing and 0 point for not practicing. The maximum possible score was 10 points with a range from $0-50$ points. Overall level of practice were classified as poor ( $<8$ points, $<50 \%$ score), moderate ( $8-11$ points, $50-79 \%$ right answer) and good (12 -15 points, $80-100 \%$ score). For logistic regression analysis practice was recoded into two groups - good (12 - 15 points, $80-100 \%$ score) and moderate to poor ( $<12$ points, $<80 \%$ score).

\section{Data collection}

Data was collected between November 15, 2021 and February 15, 2021. We have dissiminated our online questionnaire through our professional network using emails and WhatsApp. Participants were requested to avoid multi-registration. Before starting data collection we have pretesed our online questionnaire on $20 \mathrm{HCWs}$ from different facilities. Pretesting feedback was used to improve wording of the questions and response options. 
A total of 213 HCWs participated in the survey out of a total of 278 HCWs in the Qassim univerity medical city with a response rate of $76.62 \%$.

\section{Statistical analysis}

Data was analysed using the SPSS version 20. Descriptive analyses were carried out to analyze participants' demographic information, mean knowledge, attitude and practice score of the HCWs. Descriptive analyses results were presented in tables reporting percentages and frequencies. To investigate association between KAP and socio-demographic variables, we conducted multivaraible logistic regression analyses and independent sample $t$ tests. A $p$ value of $<.05$ were considered statistically significant for both tests. For multivariable logistic regression analyses, we reported odds ratio (OR) with $95 \%$ confidence interval (CI). To compare mean knowledge, attitude and practice between different socio-demographic and professional groups we did independent sample $t$ test. For these tests we reported mean knowledge, attitude and practice score of different groups and reported mean differences with $95 \% \mathrm{CI}$.

\section{Results}

A total of 213 health-care workers (HCWs) participanted in this study. Among them, $67.1 \%$ were aged $30-34$ years ; $56.3 \%$ of were males ; $67.6 \%$ had more than 6 years of experience as a HCW; $30.5 \%$ were previously exposed to infection while working and $84.5 \%$ received training in infection control practices (Table 1 ).

Table 1. Socio -demographics characteristics of the health-care workers, assessment of KAP of standard infection control precautions, Qassim medical city, KSA.

\begin{tabular}{cc}
\hline Total Charactristics & Count (\%) \\
Gender & $120(56.3)$ \\
Male & $93(43.7)$ \\
Female & \\
Age group & $143(67.1)$ \\
$22-34$ & $70(32.9)$ \\
235 years & $69(32.4)$ \\
Work experience & $144(67.6)$ \\
$0-6$ years & \\
$>6$ years & $65(30.5)$ \\
Exposed to infection while working & $148(69.5)$ \\
Yes & $180(84.5)$ \\
No & $33(15.5)$ \\
Received training on infection control & \\
Yes & \\
No &
\end{tabular}

Table 2. Knowledge of the health-care workers on infection control standard precautions, Qassim medical city, KSA.

\begin{tabular}{|c|c|c|c|}
\hline \multirow{2}{*}{\multicolumn{2}{|c|}{ Knowledge questions (correct response) }} & \multicolumn{2}{|c|}{ Correct responses } \\
\hline & & Count & $\%$ \\
\hline 1. & $\begin{array}{l}\text { Standard precautions are used for the care of all patients regardless of their diagnosis and perceived } \\
\text { infection status (Yes). }\end{array}$ & 205 & 96.2 \\
\hline & 2. Isolation precaution is one of the elements in standard precaution (Yes). & 162 & 76.1 \\
\hline 3. & $\begin{array}{l}\text { Washing hands after contact with the patient's environment is one of the elements in standard pre- } \\
\text { caution (Yes). }\end{array}$ & 204 & 95.8 \\
\hline & Alcohol-based rubs are used after removing gloves (Yes). & 122 & 57.3 \\
\hline & Performing hand hygiene is required before and after patient care (Yes). & 205 & 96.2 \\
\hline 6. & $\begin{array}{l}\text { Hands should be washed with soap and water before and after handling potentially infectious mate- } \\
\text { rials irrespective of wearing gloves (Yes). }\end{array}$ & 200 & 93.9 \\
\hline 7. & $\begin{array}{l}\text { PPE is important in infection control because acts as a barrier between infectious materials such as } \\
\text { viral and bacterial contaminants and your skin, mouth, nose, or eyes (mucous membranes) (Yes). }\end{array}$ & 166 & 77.9 \\
\hline & 8. Gloves must be worn every time during handling potentially infectious materials (Yes). & 209 & 98.1 \\
\hline
\end{tabular}


9. Gloves must be changed during patient care if you move hands from 'contaminated body site' to 'clean body site' (Yes).

10. Surgical masks can protect the nose and mouth when procedures and activities are likely to gene-

rate splashes or sprays of blood and body fluids (Yes).

11. The purpose of using a gown or apron is to protect clothes from splashes or sprays of blood and

body fluids (Yes).
12. Removed all personal protective equipment (PPE) before leaving the patient's environment (Yes).

13. Stationary, telephones kept in wards, and doorknobs can be sources of infections (Yes).

14. All linen from an infectious patient should be thrown in a red linen bag even when it is free from visible blood or body fluids (Yes).

15. Segregation of clinical and non-clinical waste is important for preventing spread of infection (Yes). 16. Ampoules injection that has been used must be disposed of in the clinical waste bin (Yes).

17. Recapping of needles, in general, is not appropriate (Yes).

20. Mask must be placed on coughing patients to prevent potential dissemination of infectious respiratory secretions from the patient to others (Yes).

$$
\begin{gathered}
\text { Poor } \\
\text { Moderate } \\
\text { Good }
\end{gathered}
$$

Mean score $( \pm \mathrm{SD})$

Knowledge score range

\begin{tabular}{cc}
13 & 6.1 \\
56 & 26.3 \\
144 & 67.6 \\
$15.7( \pm 2.7)$ \\
\multicolumn{2}{c}{$9-20$}
\end{tabular}

Table 2 depicts the number of the participants with the correct responses in each knowledge statement. We found that $67.6 \%$ of the HCWs had good knowlege ( $\geq 80 \%$ correct response) about infection control standard precautions. The mean score for knowledge was $15.7( \pm 2.7)$ with a range from $9-20$.

We found that majority of the HCWs correctly responded to the knowledge statments related to using standard precautions for all patients regardless of their diagnosis and perceived infection status (96.2\%) and isolation precaution $(76.1 \%)$, performing hand hygine after contact with the patient's environment $(95.8 \%)$, before and after patient care $(96.2 \%)$ and before and after handling potentially infectious materials (93.9\%). Moreover, they correctly responded to the knowledge statments related to wearing $(98.1 \%)$ and changing gloves $(95.8 \%)$ for each patients; using surgical masks $(86.1 \%)$ and gown or apron $(85.4 \%)$ to block contaminants and segregation of clinical and non-clinical waste for preventing spread of infection and (96.2\%). All participants stated that mask must be placed on coughing patients to prevent potential dissemination of infectious respiratory secretions from the patient to others. While fewer participants correctly responded to statments related to linen from an infectious patients $(45.5 \%)$, throwing of ampoules injection that has been used in the clinical waste bin (37.1\%) and only $10.3 \%$ of them consid-

\begin{tabular}{|c|c|c|c|}
\hline \multirow{2}{*}{\multicolumn{2}{|c|}{ Items used to assess attitude (positive attitude) }} & \multicolumn{2}{|c|}{ Positive attitude } \\
\hline & & \multirow{2}{*}{$\begin{array}{c}\text { Count } \\
82\end{array}$} & \multirow{2}{*}{$\begin{array}{c}\% \\
38.5\end{array}$} \\
\hline & Standard precaution is not easy to follow (strongly disagree). & & \\
\hline 2. & $\begin{array}{l}\text { Standard precautions prevent the spread of infections from patients to HCWs and vice versa } \\
\text { (strongly agree). }\end{array}$ & 187 & 87.8 \\
\hline \multirow{3}{*}{4.} & 3. Infectious diseases can be treated hence PPE are not required (strongly disagree). & 117 & 54.9 \\
\hline & Prefers to perform handhygine before and after any intervention with patients (strongly agree). & 195 & 91.5 \\
\hline & 5. PPE can be used during emergencies (strongly agree). & 94 & 44.1 \\
\hline 6. & $\begin{array}{c}\text { Changing gloves is not necessary during procedures even if heavily contaminated (strongly di- } \\
\text { sagree). }\end{array}$ & 176 & 82.6 \\
\hline \multirow[b]{2}{*}{8.} & It is difficult to work wearing PPE (strongly disagree). & 27 & 12.7 \\
\hline & $\begin{array}{l}\text { Healthcare providers should ensure the availability of adequate protective barriers (strongly } \\
\text { agree). }\end{array}$ & 145 & 68.1 \\
\hline 9. & HCWs should not use PPE because it may harm patients psychologically (strongly disagree). & 129 & 60.6 \\
\hline 10 . & Stationeries, telephones, and doorknobs are not sources of infections (strongly disagree). & 158 & 74.2 \\
\hline
\end{tabular}
ered stationary, telephones kept in wards, and doorknobs as sources of infections.

Table 3. Attitude of the health-care workers towards standard infection control precautions, Qassim medical city, KSA. 
11. Segregation of clinical and non-clinical waste is useful to prevent transmission of infections from one to another (strongly agree).

12. Adequate disinfection of medical equipment should be ensured by all HCWs (strongly agree)

13. Transmission of infectious organisms can be reduced by adhering to standard and contact precautions (strongly agree).

14. It is not logical to assume all patients contagious unless their infection has been confirmed (strongly disagree).

Overall level of attitude

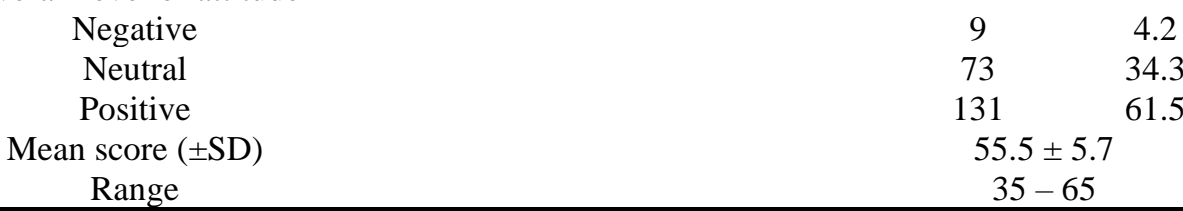

The results presented in Table 3 showed that $61.5 \%$ of study participants had positive attitudes twords infection control standard precaution. The mean score for attitudes was (55.5 \pm 5.7$)$ with a range $35-65$. The Majority of the HCWs had a positive attitude towards performing hand-hygiene before and after any intervention with patients $(91.5 \%)$, effectiveness of standard precautions in preventing the spread of infections $(87.8 \%)$, ensuring adequate disinfection of medical equipment $(85.0 \%)$, reducing the transmission of infectious organisms by adhering to standard and contact precautions $(78.4 \%)$ and considered stationeries, telephones, and doorknobs are sources of infections (74.2\%).

However, only $38.5 \%, 16 \%$ and $12.7 \%$ respectively strongly disagreed to the statements that standard precautions is not easy to follow, it is not logical to assume all patients contagious unless their infection has been confirmed and it is difficult to work wearing PPE. Therefore, demonstrated negative attitudes in these regards (Table 3).

Table 4. Practice of standard infection control precaution among the health-care workers, Qassim Medical City, KSA.

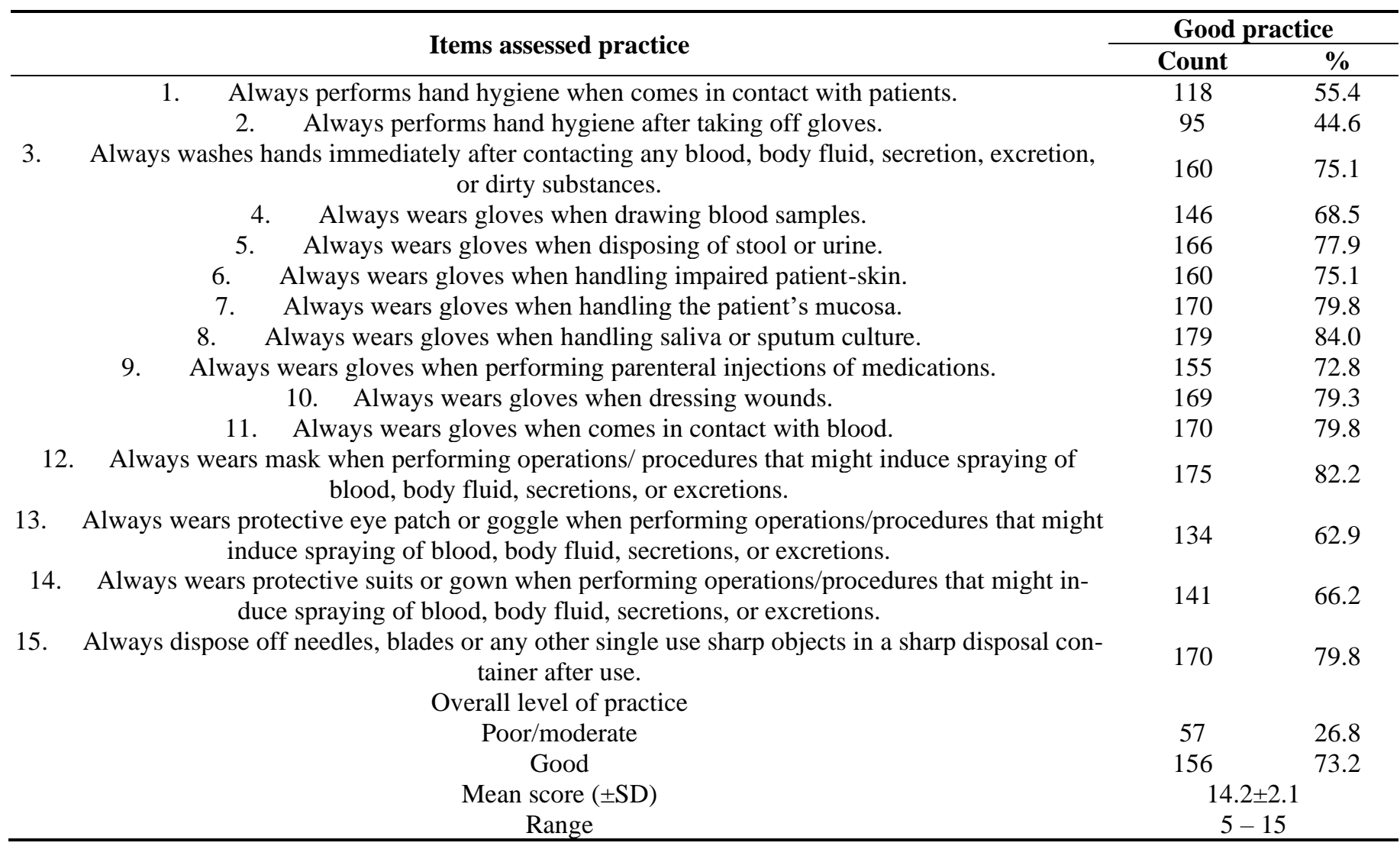

With regard to practices of the HCWs' infection control standard precautions, Table 4 shows that $73.3 \%$ of participants had good practice of infection control standard precaution ( $\geq 80 \%$ score). Mean practice score (14.2) was closer to the maximum attainable score (15). Among the participants, $84.4 \%$ reported always wearing gloves when handling 
saliva or sputum culture ; $82.2 \%$ reported always wearing mask when performing operations / procedures that might induce spraying of blood, body fluid, secretions, and excretions. Moreover, majority of them reported always wears gloves when comes in contact with blood or handling the patient's mucosa $(79.8 \%)$, dressing wounds $(79.3 \%)$, disposing of stool or urine $(77.9 \%)$, handling impaired patient-skin $(75.1 \%)$, performing parenteral injections of medications (72.8\%) and drawing blood samples $(68.5 \%)$.

In relation to hand hygeine, $75.1 \%$ of the participants allways performed hand hygiene immediately after contacting blood, body fluid, secretion, excretion, and dirty substances. However, only 55.4\% reported performing hand hygine when comes in contact with patients and $44.6 \%$ reported reported performing hand hygine after taking off gloves. While study participnats had allways wears protective suits or gown $66.2 \%$ and protective eye patch or goggle $(62.9 \%)$ when performing operations/procedures that might induce spraying of blood, body fluid, secretions, and excretions. With regard to the waste disposal, 79.8\% of the participants reported always disposing of single use needles, blades and other sharp objectes in a sharp disposal box after use.

Table 5. Association between sociodemographic characteristics and level of knowledge, attitude and practice of standard infection control precautions among the health-care workers, Qassim university medical city, KSA.

Knowledge

Attitude

Practices

\section{Charachteristi}

cs Poor/mo

derate

$(n, \%)$

$\begin{array}{ccc}\text { Good } & \text { OR }(95 \% \\ (n, \%) & p & \text { CI })\end{array}$

Poor $/ \mathrm{m}$
oderate
$(n, \%)$$(n, \%)$

p OR $(95 \%$
CI $)$

Poor $/ \mathrm{m}$
oderate
$(n, \%)$

$\begin{array}{ccc}\text { Good } & \text { OR } \\ (n, \%) & p & \left(\begin{array}{c}95 \% \\ \text { CI })\end{array}\right.\end{array}$

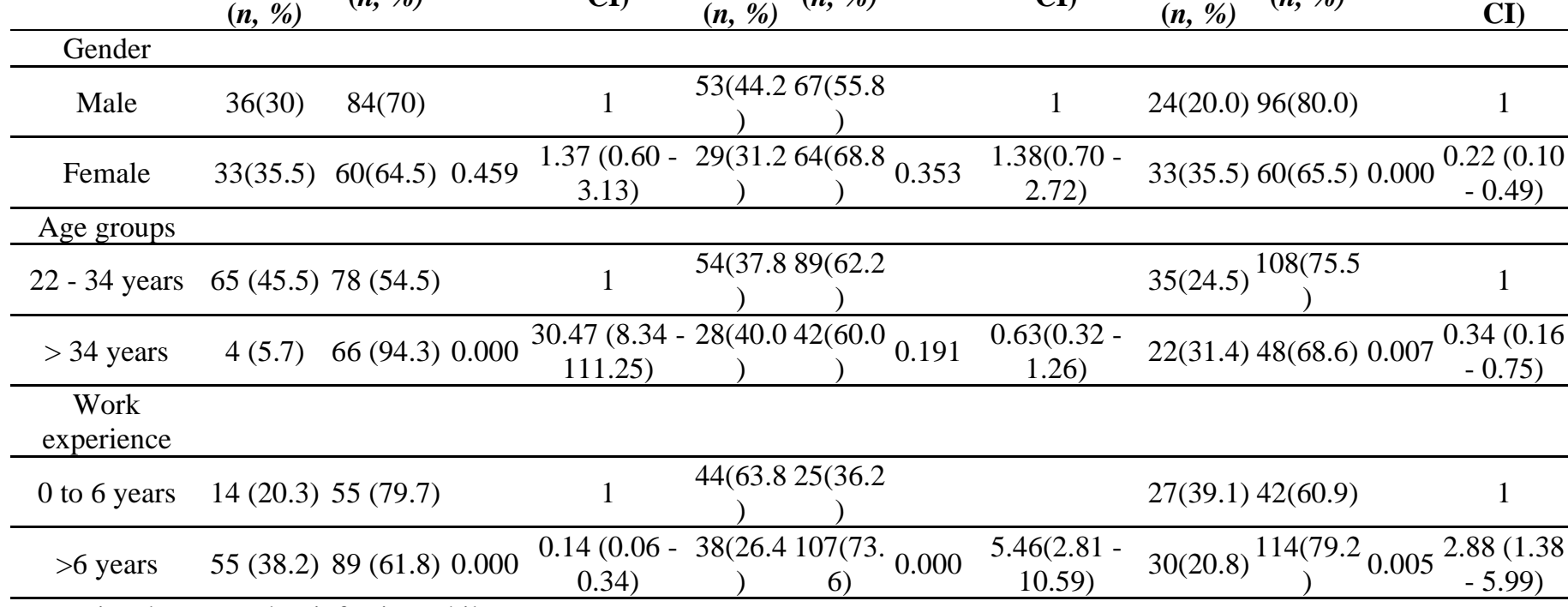

Previously exposed to infection while

working

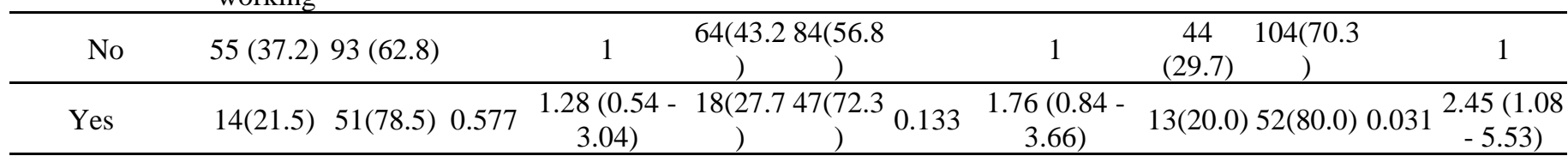

Received training in infection

control

\begin{tabular}{|c|c|c|c|c|c|c|c|c|}
\hline \multirow{2}{*}{ No } & \multirow{2}{*}{$21(63.6)$} & \multirow{2}{*}{$12(36.4)$} & \multirow{2}{*}{1} & \multicolumn{2}{|l|}{$17(51.516(48.5$} & \multirow{2}{*}{1} & \multirow{2}{*}{$17(51.5) 16(48.5)$} & \multirow{2}{*}{1} \\
\hline & & & & ) ） & & & & \\
\hline Yes & $69(26.7)$ & $\begin{array}{c}132(73.3 \\
)\end{array}$ & $\begin{array}{c}13.26(4.06 \\
43.23)\end{array}$ & $\begin{array}{cc}-65(36.1 & 115(63 . \\
) & 9)\end{array}$ & 0.563 & $\begin{array}{c}1.28(0.56- \\
2.93)\end{array}$ & $40(22.2)^{140(77.8}$ & $\begin{array}{c}0.008 \begin{array}{c}3.54(1.40 \\
-8.98)\end{array}\end{array}$ \\
\hline
\end{tabular}

Related to the factors impact the level of knowledge about standard infection control precaution, the results presented in Table 5 revealed that the older HCWs ( $>34$ years) were more likely to had good knowledge about standard precautions when compared to the younger HCWs (OR=30.47, 95\% CI : $8.34-111.25, p<0.001)$. As well, the HCWs received training on infection were 13.26 times likely to have good knowledge than the ones who did not receive such training $(\mathrm{OR}=13.3,95 \% \mathrm{CI}: 4.06-43.23, p<0.001)$. However, 
surprisingly HCWs with more than 6 years of work experience were less likely to had good knowledgel than those who have less work experince (OR : 0.14, 95\% CI : 0.06 - 0.34 , $p<0.001)$. While gender and previous exposure to infection while working did not have any statistically significant association with the level of knowledge about standard infection control precautions $(p>0.05)$

With regard to the attiude of the HCWs towards standard infection control precautions, the results showed that there is no significant association with gender, age group, previous exposure to infection and reciving training $(p>0.05)$. However, HCWs having more than 6 years of experience were more likely to have positive attitude compared to the HCWs with less experience (OR : 5.46, 95\% CI : 2.81 - 10.59, $p<0.001$ ).

Regarding the practice of infection control standard precaution, the results showed that all characteristics of the participants are statistically associated with the level of practice of standard infection control precautions. HCWs who received training on infection control (OR : $3.54,95 \% \mathrm{CI}: 1.40-8.98, p<0.01$ ), who had more than 6 years of work experience (OR : $2.88,95 \% \mathrm{CI}: 1.38-5.99, p<0.01$ ) or exposed to infection while working (OR : $2.45,95 \% \mathrm{CI}: 1.08-5.53, p<.05)$ were more likely to do good practice regarding standard infection control precautions. Gender and age were also associated with good practice. Female HCWs (OR : 0.22, 95\% CI : $0.10-0.49, p<0.001)$ and HCWs aged 35 years (OR : $0.34,95 \% \mathrm{CI}: 0.16-0.75, \mathrm{p}<0.01$ ) were less likely to do good practice compared to their counterparts.

Table 6. Differences between mean standard infection control standard precautions knowledge, attitude and practice scores between different HCWs, Qassim University Medical City, KSA.

\begin{tabular}{|c|c|c|c|c|c|c|c|c|c|}
\hline \multirow{2}{*}{$\begin{array}{l}\text { Socio-demographic } \\
\text { characteristics }\end{array}$} & \multicolumn{3}{|c|}{ Knowledge } & \multicolumn{3}{|c|}{ Attitude } & \multicolumn{3}{|c|}{ Practice } \\
\hline & Mean & $\begin{array}{l}\text { Mean difference } \\
\quad(95 \% \mathrm{CI}) *\end{array}$ & $p$ & Mean & $\begin{array}{c}\text { Mean difference } \\
(95 \% \mathrm{CI}) *\end{array}$ & $p$ & Mean & $\begin{array}{l}\text { Mean difference } \\
(95 \% \mathrm{CI}) *\end{array}$ & $p$ \\
\hline \multicolumn{10}{|l|}{ Age group } \\
\hline 22-34 years & 16.2 & $0.7(-0.04-1.5)$ & 0.061 & 51.6 & & & 13.7 & & \\
\hline$>34$ years & 15.5 & & & 57.4 & $5.8(4.3-7.3)$ & 0.000 & 14.5 & $0.8(0.3-1.5)$ & 0.003 \\
\hline \multicolumn{10}{|l|}{ Gender } \\
\hline Male & 16.0 & $0.7(0.02-1.5)$ & 0.042 & 54.4 & & & 14.5 & $0.6(0.1-1.2)$ & 0.022 \\
\hline Female & 15.3 & & & 56.9 & $2.5(1.1-3.8)$ & 0.001 & 13.9 & & \\
\hline \multicolumn{10}{|l|}{ Work experience } \\
\hline $1-6$ years & 17.6 & $0.5(0.04-1.5)$ & 0.026 & 53.3 & & & 13.7 & & \\
\hline$>6$ years & 17.1 & & & 56.8 & $3.5(2.1-4.8)$ & 0.000 & 14.5 & $0.8(0.3-1.5)$ & 0.003 \\
\hline \multicolumn{10}{|l|}{$\begin{array}{l}\text { Previously exposed to } \\
\text { infection while working }\end{array}$} \\
\hline No & 16.1 & $0.6(0.2-1.4)$ & 0.163 & 54.4 & & & 14.0 & & \\
\hline Yes & 15.5 & & & 57.5 & $3.1(1.7-4.5)$ & 0.000 & 14.8 & $0.8(0.2-1.4)$ & 0.010 \\
\hline \multicolumn{10}{|c|}{$\begin{array}{l}\text { Received training on infection } \\
\text { control }\end{array}$} \\
\hline No & 13.2 & & & 53.8 & & & 11.7 & $3.0(2.4-3.7)$ & 0.000 \\
\hline Yes & 16.2 & $3(1.9-3.8)$ & 0.269 & 55.6 & $1.8(0.7-4.3)$ & 0.166 & 14.7 & & \\
\hline
\end{tabular}

* Independent sample $t$ test. Equal variances assumed

The results in table 5 shows that HCW having less working experinces (1 to 6 years compared to more than 6 years) had significantly higher mean knowledge score (mean difference : $0.5,95 \% \mathrm{CI}$ : $0.04-1.5, p<.05)$. In addition, mean knowledge score was significantly higher among the male HCWs than the females (mean difference : 0.7, 95\% CI: 0.02 $-1.5, p<.05)$.

In case of attitudes, we found that HCWs aged 35 years or more, female, having more than 6 years of working experience and being previously exposed to infection while working had significantly higher attitude score compared to the HCWs aged less than 35 years, males, having up to 6 years of work experience and not being exposed to infection while working respectively. Surprisingly, our results showed that the training had no 
statistically significant impact on attitudes of HCWs toward infection control standard precautions $(p>.05)$.

In case of practice of standard infection control precautions we found that variables such as being younger ( $<34$ years), male, having more experience ( $>6$ years ) and receiving training on infection control were associated with significantly higher mean practice score when compared to their counterparts $(p<0.05)$.

\section{Discussion}

Knowledge is essential to develop a positive attitudes therefore is a key instigator to bring a positive change in practice $[23,24]$. Evidence suggests that knowledge and positive attitudes are associated with improved compliance with infection control standard precautions among HCWs [33]. Here we report the current status of KAP regarding standard precautions of infection control among the HCWs in the medical city of the Qassim University, KSA.

We found that just over two third of the study participants had good knowledge (gave at least $80 \%$ correct answer) about infection control standard precautions. However, this rate is still higher than the rate reported by studies conducted in a hospital in Northern Cyprus [33], among nursing students in Jordon (49.64\%) [34] and among the dental faculty members and students $\left(3^{\text {rd }}-5^{\text {th }}\right.$ year) in Riyadh, KSA (49-49.6\%) [35]. Gaps in knowledge of standard precautions among HCWs were also evident in studies conducted in Iran [36] and Nigeria [37]. This gap in knowledge among HCWs nessiseate giving more emphasis on infection control standard precautions in academic and continued professional development training curriculam.

Despite of average level of knowledge among the study participants. Most of the participants answered correctly to the knowledge statements related to using standard precautions for all patients regardless of their diagnosis, isolation precaution, and performing handhygine after contact with the patient's environment, and before and after patient care. Moreover, majority of them correctly answered the knowledge statements related to wearing and changing gloves for each patients. These finding are consistent with studies conducted in Nigeria [38] and India [39].

With regard to the attitude, our study found that the proportions of HCWs with positive attitude ( $\geq 80 \%$ score) were $61.5 \%$, which is considerably higher when compared with studies conducted in Jordon [34] and Iran [40], but lower than the proportion reported in Ethiopia (64.2\%) [41] and among the primary care professionals in Abha, KSA (88.2\%) [42]. This differences between our study and the other study in the KSA is because of using different classification system, such as any score of $\geq 60 \%$ were classified as positive attitude in the Abha study, while the cutoff point for positive attitude in our study was $80 \%$.

The majority of the HCWs had a positive attitude toward washing hands before and after any intervention with patients (91.5\%); disinfection of medical equipment $(85.0 \%)$; adhering to standard and contact precautions $(78.4 \%)$; and believed that standard precautions prevent the spread of infections (87.8\%). This is probably due to the fact that these activities became routine practice. Which probably got reinforced by a positive institution culture, policy introduced by the Ministry of Health on Infection Control.

Our study found that $73.3 \%$ HCW s had good practice ( $\geq 80 \%$ score). This rate is higher compared to the findings from studies conducted in Vietnam (46.1\%) [43], Northern Cyprus (30.9\%) [33], Ethiopia (60.2\%) [44], Iran (42\%) [40] and Singapore (66.3\% ) [45], but lower than the rate reported among nurses in India (91\%) [46]. These differences in the level of practice of infection control standard precautions in different countries may be due to the differences in education, training, organizational culture, policies, presence of infection control guidelines and monitoring of its implementation.

Our logistic regression analysis results suggest that older ( $\geq 35$ years) HCWs were more likely to have good knowledge compared to the younger HCWs ( $<35$ years). This is in contrast with the findings reported in Cyprus [33] and in Egypt [47]. These studies reported that younger HCWs (<34 years) were more likely to have good knowledge. However, another study reported no association between age and knowledge in Ethiopea [48]. 
Our results also suggest that HCWs who received training on infection control standard precautions were 13.3 times likely to have good knowledge than the HCWs without training. This indicates the importance of training in refressing and updating $\mathrm{HCWs}^{\prime}$ knowledge on infection control standard precautions. Likewise, Elliott et al. argued that intensive teaching and self-learning can improve knwoldege of HCWs in preventing sharp injuries [49]. Surprisingly, we found that those with 6 years or more work experiences were less likely to have good knowledge than the less expericed HCWs. Perhaps recent academic programs give greater emphasis on topics about infection control or infection control guidelines developed recently by the health-care facility. Therefore, lower knowledge among more experienced HCWs may be partly related to limited training on infection control. Similarly, a study in the UK reported that current medical students demonstrated better knowledge of needlestick injuries than the previous cohort [49]. Regarding association between gender and level of knowledge, we found no evidence of association. While, a study among nurses in Iran found significant association between gender and knowledge of infection control [50].

Our results also showed that sociodemographic variables such as, age, gender and training was not associated with attitude towards infection control standard precautions. This in agreement with studies conducted in Nigeria [38], Turkey [51] and in the Estern province of the KSA [52]. On the contrary, we found that HCWs having more than 6 years of experience were more likely to have positive attitude when compared to the less experienced ones. This denote that the experience is an important influenceer of attitude. While a positive attitude is highly correlated with good practice and therefore are important public health issues because these will prevent spread of infection from the health-care facilities [53].

Regarding the practice of infection control standard precautions, our results showed that all characteristics of the participants like, age, gender, experience and training were statistically significantly associated with good practices. This is consistent with studies conducted by AlKhaldi et al. who reported that good practice was significantly associated with years of experience and training in infection control [42]. A similar study in Korea reported that gender, work experience, age and training course are significantly associated with practice [54]. Therefore, it is important that health-care facilities organize regular training programs on infection control standard precuations for the HCWs to refress and update their knowledge and promote positive attitude and good practice.

\section{Conclusion}

Having good knowledge, attitude and practice of infection control standard precautions are vital to prevent the spread of infections from health-care facilities. Our research highlighted the gaps in KAP of the HCWs practicing in a teaching hospital in Qassim, KSA. Years of experience was negatively associated with knowledge which might indicate that older academic programs did not adequately covered topics on infection crontrol in health-care facilities. We further found that receivng training on infection control standard precautions is positively associated with good knowledge and practice. Therefore, arranging training programs for HCWs might be useful in refressing and improving their knowledge of infection control standard precautions and is also expected to facilitate positve attitude and practice.

Author Contributions: Conceptualization, I.M. and AA; methodology, I.M and A.A.; formal analysis, Y.M.E., and I.M.; investigation, A.A. , M.J., K.A., F.A.A., and T.A.; resources, A.A.; data curation, A.A. , M.J., K.A., F.A.A., and T.A..; writing-original draft preparation, M.H.A.; Y.M.E and I.M.; writing - review and editing, I.M., M.H.A., A.A., M.J., K.A., F.A.A., and T.A; visualization, I.M.; supervision, I.M., and A.A..; project administration, A.A. , M.J., K.A., F.A.A., and T.A; funding acquisition, A.A. All authors have read and agreed to the published version of the manuscript.

Funding: This research received no external funding. 
Institutional Review Board Statement: The study was conducted according to the guidelines of the Declaration of Helsinki, and ethical approval was obtained from the Qassim Regional Ethics Committee (IRB number: 1442-4-228).

Informed Consent Statement: Informed consent was obtained from all subjects involved in the study.

Data Availability Statement: Data used in this study are available from the corresponding author on reasonable request.

Acknowledgments: The researchers would like to thank the Deanship of Scientific Research, Qassim University for funding the publication of this project.

Conflicts of Interest: The authors declare no conflicts of interest. The funders had no role in the design of the study; in the collection, analyses, or interpretation of data; in the writing of the manuscript, or in the decision to publish the results.

\section{References}

1. Breathnach, A.S. Nosocomial infections and infection control. Medicine 2013, 41, 649-653.

2. Moralejo, D.; El Dib, R.; Prata, R.A.; Barretti, P.; Corrêa, I. Improving adherence to Standard Precautions for the control of health care - associated infections. Cochrane Database of Systematic Reviews 2018.

3. World Health Organization. Report on the Burden of Endemic Health Care-Associated Infection Worldwide: A systematic review of the literature; Geneva: World Health Organization, 2011.

4. Magill, S.S.; O'Leary, E.; Janelle, S.J.; Thompson, D.L.; Dumyati, G.; Nadle, J.; Wilson, L.E.; Kainer, M.A.; Lynfield, R.; Greissman, S.; et al. Changes in Prevalence of Health Care-Associated Infections in U.S. Hospitals. N Engl J Med 2018, 379, 17321744, doi:10.1056/NEJMoa1801550.

5. Suetens, C.; Latour, K.; Kärki, T.; Ricchizzi, E.; Kinross, P.; Moro, M.L.; Jans, B.; Hopkins, S.; Hansen, S.; Lyytikäinen, O. Prevalence of healthcare-associated infections, estimated incidence and composite antimicrobial resistance index in acute care hospitals and long-term care facilities: results from two European point prevalence surveys, 2016 to 2017. Eurosurveillance 2018, $23,1800516$.

6. Habibi, S.; Wig, N.; Agarwal, S.; Sharma, S.K.; Lodha, R.; Pandey, R.M.; Kapil, A. Epidemiology of nosocomial infections in medicine intensive care unit at a tertiary care hospital in northern India. Trop Doct 2008, 38, 233-235, doi:10.1258/td.2008.070395.

7. Lahsaeizadeh, S.; Jafari, H.; Askarian, M. Healthcare-associated infection in Shiraz, Iran 2004-2005. J Hosp Infect 2008, 69, 283-287, doi:10.1016/j.jhin.2008.05.006.

8. Daxboeck, F.; Budic, T.; Assadian, O.; Reich, M.; Koller, W. Economic burden associated with multi-resistant Gram-negative organisms compared with that for methicillin-resistant Staphylococcus aureus in a university teaching hospital. J Hosp Infect 2006, 62, 214-218, doi:10.1016/j.jhin.2005.07.009.

9. Andersson, A.E.; Bergh, I.; Karlsson, J.; Nilsson, K. Patients' experiences of acquiring a deep surgical site infection: an interview study. Am J Infect Control 2010, 38, 711-717, doi:10.1016/j.ajic.2010.03.017.

10. Byarugaba, D.K. A view on antimicrobial resistance in developing countries and responsible risk factors. Int J Antimicrob Agents 2004, 24, 105-110, doi:10.1016/j.ijantimicag.2004.02.015.

11. Adebimpe, W.O.; Olufunmilayo, A.-O.E.; Bamidele, J.O.; Lanre, A.O.; Adekunle, O. A comparative study of awareness and attitude to nosocomial infections among levels of health care workers in Southwestern Nigeria. Continental Journal of Tropical Medicine 2011, 5, 5 .

12. Wu, W.; Wang, W.; Yuan, Y.; Lin, L.; Tan, Y.; Yang, J.; Dai, L.; Wang, Y. Knowledge, attitude and practice concerning healthcare-associated infections among healthcare workers in Wuhan, China: cross-sectional study. BMJ Open 2021, 11, e042333, doi:10.1136/bmjopen-2020-042333. 
13. Koch, A.M.; Nilsen, R.M.; Eriksen, H.M.; Cox, R.J.; Harthug, S. Mortality related to hospital-associated infections in a tertiary hospital; repeated cross-sectional studies between 2004-2011. Antimicrobial Resistance and Infection Control 2015, 4, 57, doi:10.1186/s13756-015-0097-9.

14. World Health Organization. Health care-associated infections; Geneva: WHO., 2016.

15. Siegel, J.D.; Rhinehart, E.; Jackson, M.; Chiarello, L. 2007 Guideline for Isolation Precautions: Preventing Transmission of Infectious Agents in Health Care Settings. Am J Infect Control 2007, 35, S65-164, doi:10.1016/j.ajic.2007.10.007.

16. Hien, H.; Drabo, M.; Ouédraogo, L.; Konfé, S.; Sanou, D.; Zéba, S.; Compaoré, S.C.; Ouédraogo, J.B.; Meda, N. [Knowledge and practices of health care workers in the area of healthcare-associated infection risks. A case study in a district hospital in Burkina Faso]. Sante Publique 2013, 25, 219-226.

17. Jin, Y.H.; Huang, Q.; Wang, Y.Y.; Zeng, X.T.; Luo, L.S.; Pan, Z.Y.; Yuan, Y.F.; Chen, Z.M.; Cheng, Z.S.; Huang, X.; et al. Perceived infection transmission routes, infection control practices, psychosocial changes, and management of COVID-19 infected healthcare workers in a tertiary acute care hospital in Wuhan: a cross-sectional survey. Mil Med Res 2020, 7, 24, doi:10.1186/s40779-020-00254-8.

18. Patarakul, K.; Tan-Khum, A.; Kanha, S.; Padungpean, D.; Jaichaiyapum, O.O. Cross-sectional survey of hand-hygiene compliance and attitudes of health care workers and visitors in the intensive care units at King Chulalongkorn Memorial Hospital. J Med Assoc Thai 2005, 88 Suppl 4, S287-293.

19. Batuduwaarachchi, V.; Balasubramanium, M.; Balasooriya, D.; Senerath, L. Compliance with aseptic procedures during intravenous access among the nursing staff at the National Hospital of Sri Lanka. International Journal of Infection Control 2011, $7,1-6$.

20. Memish, Z.A. Infection control in Saudi Arabia: meeting the challenge. Am J Infect Control 2002, 30, 57-65, doi:10.1067/mic.2002.120905.

21. Al Ra'awji, B.A.; Almogbel, E.S.; Alharbi, L.A.; Alotaibi, A.K.; Al-Qazlan, F.A.; Saquib, J. Knowledge, attitudes, and practices of health-care workers regarding hand hygiene guidelines in Al-Qassim, Saudi Arabia: A multicenter study. International journal of health sciences $2018,12,3$.

22. Hamid, H.A.; Mustafa, M.M.; Al-Rasheedi, M.; Balkhi, B.; Suliman, N.; Alshaafee, W.; Mohammed, S.A. Assessment of hospital staff knowledge, attitudes and practices (KAPS) on activities related to prevention and control of hospital acquired infections. J Infect Prev 2019, 10.

23. Kelman, H.C. The role of action in attitude change. In Proceedings of the Nebraska symposium on motivation, 1979.

24. Jiang, H.; Zhang, S.; Ding, Y.; Li, Y.; Zhang, T.; Liu, W.; Fan, Y.; Li, Y.; Zhang, R.; Ma, X. Development and validation of college students' tuberculosis knowledge, attitudes and practices questionnaire (CS-TBKAPQ). BMC Public Health 2017, 17, 949, doi:10.1186/s12889-017-4960-x.

25. Assiri, K.I.; Kaleem, S.M.; Ibrahim, M.; Alam, T.; Asif, S.M. Knowledge, attitude, and practice of infection control among dental students in King Khalid University, Abha. journal of international oral health 2018, 10, 83.

26. Al-Shamiri, H.-M.; AlShalawi, F.-E.; AlJumah, T.-M.; AlHarthi, M.-M.; AlAli, E.-M.; AlHarthi, H.-M. Knowledge, attitude and practice of hepatitis B virus infection among dental students and interns in Saudi Arabia. Journal of clinical and experimental dentistry 2018, 10, e54.

27. Shah, F.A.; Alanazi, A.O.; Alrawili, Y.K.; Alanazi, Y.M. Knowledge and attitudes towards infection control protocols among the students of Al-Jouf University in Saudi Arabia. The Egyptian Journal of Hospital Medicine 2018, 71, 3328-3331.

28. AlAhdal, A.; Aljehani, W.; Ali, G.; Bayoumi, A. Knowledge, attitude and practice of infection control measures in private dental clinics in Jeddah, Saudi Arabia. Int J Dent Oral Health 2019, 5, 1-6.

29. Ibrahim, N.K.; Alwafi, H.A.; Sangoof, S.O.; Turkistani, A.K.; Alattas, B.M. Cross-infection and infection control in dentistry: Knowledge, attitude and practice of patients attended dental clinics in King Abdulaziz University Hospital, Jeddah, Saudi Arabia. Journal of infection and Public Health 2017, 10, 438-445. 
30. Khubrani, A.; Albesher, M.; Alkahtani, A.; Alamri, F.; Alshamrani, M.; Masuadi, E. Knowledge and information sources on standard precautions and infection control of health sciences students at King Saud bin Abdulaziz University for Health Sciences, Saudi Arabia, Riyadh. Journal of infection and public health 2018, 11, 546-549.

31. Prevention, C.f.D.C.a. Standard Precautions. Available online: https://www.cdc.gov/oralhealth/infectioncontrol/summaryinfection-prevention-practices/standard-precautions.html (accessed on September 9).

32. World Health Organization. Infection control standard precautions in health care. Available online: https://www.who.int/csr/resources/publications/4EPR_AM2.pdf (accessed on September 9).

33. Abuduxike, G.; Acar Vaizoglu, S.; Asut, O.; Cali, S. An Assessment of the Knowledge, Attitude, and Practice Toward Standard Precautions Among Health Workers From a Hospital in Northern Cyprus. Safety and Health at Work 2021, 12, 66-73, doi:https://doi.org/10.1016/j.shaw.2020.09.003.

34. Darawad, M.W.; Al-Hussami, M. Jordanian nursing students' knowledge of, attitudes towards, and compliance with infection control precautions. Nurse education today 2013, 33, 580-583, doi:10.1016/j.nedt.2012.06.009.

35. Alharbi, G.; Shono, N.; Alballaa, L.; Aloufi, A. Knowledge, attitude and compliance of infection control guidelines among dental faculty members and students in KSU. BMC oral health 2019, 19, 7, doi:10.1186/s12903-018-0706-0.

36. Askarian, M.; McLaws, M.-L.; Meylan, M. Knowledge, attitude, and practices related to standard precautions of surgeons and physicians in university-affiliated hospitals of Shiraz, Iran. Int J Infect Dis 2007, 11, 213-219, doi:10.1016/j.ijid.2006.01.006.

37. Okechukwu, E.F.; Motshedisi, C. Knowledge and practice of standard precautions in public health facilities in Abuja, Nigeria. nternational Journal of Infection Control 2012, 8, doi:doi.org/10.3396/ijic.v8i3.10003.

38. Ogoina, D.; Pondei, K.; Adetunji, B.; Chima, G.; Isichei, C.; Gidado, S. Knowledge, attitude and practice of standard precautions of infection control by hospital workers in two tertiary hospitals in Nigeria. J Infect Prev 2015, 16, 16-22, doi:10.1177/1757177414558957.

39. Debbarma, M.; Gogoi, S.; Jais, M.; Gupta, P.; Sharma, P.; Kaur, R. Knowledge, attitude and practice of standard precautions among the health care workers of a tertiary care teaching hospital of north India. International Journal of Contemporary Medical Research 2015, 2, 1282-1285.

40. Sarani, H.; Balouchi, A.; Masinaeinezhad, N.; Ebrahimitabas, E. Knowledge, Attitude and Practice of Nurses about Standard Precautions for Hospital-Acquired Infection in Teaching Hospitals Affiliated to Zabol University of Medical Sciences (2014). Global journal of health science 2015, 8, 193-198, doi:10.5539/gjhs.v8n3p193.

41. Yazie, T.D.; Sharew, G.B.; Abebe, W. Knowledge, attitude, and practice of healthcare professionals regarding infection prevention at Gondar University referral hospital, northwest Ethiopia: a cross-sectional study. BMC Res Notes 2019, 12, 563-563, doi:10.1186/s13104-019-4605-5.

42. Al-Ahmari, A.M.; AlKhaldi, Y.M.; Al-Asmari, B.A. Knowledge, attitude and practice about infection control among primary care professionals in Abha City, Kingdom of Saudi Arabia. J Family Med Prim Care 2021, 10, 662-668, doi:10.4103/jfmpc.jfmpc_1278_20.

43. Thu, T.A.; Anh, N.Q.; Chau, N.Q.; Hung, N.V. Knowledge, attitude and practices regarding standard and isolation precautions among vietnamese health care workers: a multicenter cross-sectional survey. Intern Med 2012, 2, doi:10.4172/2165-8048.1000115. 44. Asmr, Y.; Beza, L.; Engida, H.; Bekelcho, T.; Tsegaye, N.; Aschale, Y. Assessment of Knowledge and Practices of Standard Precaution against Blood Borne Pathogens among Doctors and Nurses at Adult Emergency Room in Addis Ababa, Ethiopia. Emergency medicine international 2019, 2019, 2926415, doi:10.1155/2019/2926415.

45. Nasirudeen, A.M.; Koh, J.W.; Lau, A.L.; Li, W.; Lim, L.S.; Ow, C.Y. Hand hygiene knowledge and practices of nursing students in Singapore. Am J Infect Control 2012, 40, e241-243, doi:10.1016/j.ajic.2012.02.026.

46. Kaushal, G.; Doke, P.; Shah, A.; Verma, V. An Analysis of Knowledge, Attitude and Practices regarding Standard Precautions of Infection Control and Impact of Knowledge and Attitude of ICU Nurses on Self-reported Practices of Infection Control. Int J Res Foundation Hosp Healthc Adm 2015, 3, 79-85. 
47. Hakim, S.A.; Mohsen, A.; Bakr, I. Knowledge, attitudes and practices of health-care personnel towards waste disposal management at Ain Shams University Hospitals, Cairo. Eastern Mediterranean health journal = La revue de sante de la Mediterranee orientale = al-Majallah al-sihhiyah li-sharq al-mutawassit 2014, 20, 347-354.

48. Beyamo, A.; Dodicho, T.; Facha, W. Compliance with standard precaution practices and associated factors among health care workers in Dawuro Zone, South West Ethiopia, cross sectional study. BMC Health Services Research 2019, 19, 381, doi:10.1186/s12913-019-4172-4.

49. Elliott, S.K.; Keeton, A.; Holt, A. Medical students' knowledge of sharps injuries. J Hosp Infect 2005, 60, 374-377, doi:10.1016/j.jhin.2005.01.033.

50. Ghadmgahi F.; Zighaimat F.; Ebadi A.; Houshmand A. Knowledge, attitude and self-efficacy of nursing staffs in hospital infections control. Journal of Military Medicine 2011, 13, 167-172.

51. Hosoglu, S.; Akalin, S.; Sunbul, M.; Otkun, M.; Ozturk, R. Healthcare workers' compliance with universal precautions in Turkey. Medical hypotheses 2011, 77, 1079-1082, doi:10.1016/j.mehy.2011.09.007.

52. Elsherbeny, E.E.; Shatla, M.M.; Niazy, N.A.; Hamied, A.M.A.E.; El-Masry, R. Physicians' and nurses' adherence to standard precautions in a tertiary health care facility in the eastern province, Saudi Arabia. Egyptian Journal of Occupational Medicine 2018, 42, 33-44, doi:10.21608/ejom.2018.4937.

53. AlJohani, A.; Karuppiah, K.; Al Mutairi, A.; Al Mutair, A. Narrative Review of Infection Control Knowledge and Attitude among Healthcare Workers. J Epidemiol Glob Health 2021, 11, 20-25, doi:10.2991/jegh.k.201101.001.

54. Oh, E.; Choi, J.S. Factors influencing the adherence of nurses to standard precautions in South Korea hospital settings. Am J Infect Control 2019, 47, 1346-1351, doi:10.1016/j.ajic.2019.05.015. 